\title{
Expression of Vitreoscilla hemoglobin in Gordonia amarae enhances biosurfactant production
}

Received: 22 June 2005 / Accepted: 29 January 2006/Published online: 21 February 2006

(C) Society for Industrial Microbiology 2006

\begin{abstract}
The gene ( $v g b$ ) encoding Vitreoscilla (bacterial) hemoglobin ( $\mathrm{VHb}$ ) was electroporated into Gordonia amarae, where it was stably maintained, and expressed at about $4 \mathrm{nmol} \mathrm{VHb} \mathrm{g}^{-1}$ of cells. The maximum cell mass $\left(\mathrm{OD}_{600}\right)$ of $v g b$-bearing $G$. amarae was greater than that of untransformed $G$. amarae for a variety of media and aeration conditions (2.8-fold under normal aeration and 3.4-fold under limited aeration in rich medium, and 3.5-fold under normal aeration and 3.2-fold under limited aeration in mineral salts medium). The maximum level of trehalose lipid from cultures grown in rich medium plus hexadecane was also increased for the recombinant strain, by 4.0 -fold in broth and 1.8 -fold in cells under normal aeration and 2.1-fold in broth and 1.4-fold in cells under limited aeration. Maximum overall biosurfactant production was also increased in the engineered strain, by 1.4-fold and 2.4-fold for limited and normal aeration, respectively. The engineered strain may be an improved source for producing purified biosurfactant or an aid to microorganisms bioremediating sparingly soluble contaminants in situ.
\end{abstract}

Keywords Bioremediation - Biosurfactant production Gordonia amarae · Trehalose lipid production . Vitreoscilla hemoglobin

I. Dogan · D. A. Webster · B. C. Stark $(\bowtie)$

Biology Division, Department of Biological, Chemical, and Physical Sciences, Illinois Institute of Technology,

IIT Center, Chicago, IL 60616, USA

E-mail: starkb@iit.edu

Tel.: + 1-312-5673488

Fax: + 1-312-5673494

K. R. Pagilla

Department of Chemical and Environmental Engineering, Illinois Institute of Technology, Chicago, IL 60616, USA

Present address: I. Dogan

Department of Molecular Biology and Genetics,

Izmir Institute of Technology, Izmir, Turkey

\section{Introduction}

Release of organic contaminants into the environment can be problematic because of their toxicity and their stability. Bioremediation by microorganisms, however, can often be an effective method to clean up contaminated sites [29].

Use of biologically produced surfactants as a tool in bioremediation has become a subject of increasing study, as they can dramatically increase the apparent solubility of insoluble and sparingly soluble compounds so that they can be taken up by cells and metabolized [19]. Biosurfactants are produced and released by microorganisms during growth on insoluble substrates in water [7]. They are currently used in several applications, including bioremediation, in which, unlike synthetic surfactants, they themselves are biodegradable and pose no additional pollution threat. Furthermore, most studies indicate that they are non-toxic to microorganisms and therefore are unlikely to inhibit biodegradation [2].

As with other microbial fermentations the goal in production of biosurfactants is to maximize productivity, and achieve high final concentrations [12]. In this way it is possible that solubilization and biodegradation rates of insoluble substrates can be increased by microorganisms. It has been reported that Nocardia species that are grown on hydrocarbons produce biosurfactants $[23,25]$. In particular, the bacterium Gordonia amarae (previously known as Nocardia amarae) has been shown to produce biosurfactants that enhance removal of nonionic organic contaminants from water $[28,36]$.

It has been demonstrated that expression of bacterial hemoglobin $(\mathrm{VHb})$ in heterologous bacterial hosts engineered to contain the $\mathrm{VHb}$ gene $(\mathrm{vg} b)$ often results in enhancement of cell density, oxidative metabolism, protein and antibiotic production, and bioremediation, especially under oxygen-limiting conditions $[17,24,35$, 39, 40]. The beneficial effects of $v g b$ have also been demonstrated in a variety of eukaryotes. These include 
enhancement of antibiotic production in fungi [9], tissue plasminogen activator production in mammalian cells [31], and growth in plants and plant cell cultures $[11,14]$. There is evidence that the beneficial effects in bacteria are the result of direct interaction of $\mathrm{VHb}$ with the terminal respiratory oxidase, delivering oxygen to it to enhance oxidative phosphorylation and thus the production of ATP [16, 30, 32]. In the case of bioremediation enhancement, a direct delivery of oxygen by $\mathrm{VHb}$ to oxygenases which degrade aromatics may occur $[20,21]$.

In the work reported here, $v g b$ was electroporated into $G$. amarae and expressed in the resulting recombinant cells where it enhanced both growth and biosurfactant production. This is the first report in which engineering with $v g b$ has been used in this way as a possible strategy to enhance biodegradation of sparingly soluble compounds. It suggests that engineering of biosurfactant-producing bacteria with $v g b$ may be a useful way to extend the possible uses of $v g b$ in strain improvement for bioremediation.

\section{Materials and methods}

Bacterial strains, plasmids, and media

Gordonia amarae (NRRL B-8176) was provided by the USDA National Center for Agriculture Utilization Research (Peoria, IL, USA). Plasmid pSC160 had been constructed [22] by inserting linearized pUC8:16 (which carries $v g b$ on a $1.4 \mathrm{~kb}$ fragment from Vitreoscilla strain $\mathrm{C} 1$ [10] cloned into vector pUC8) into the EcoRI site of broad host range vector pKT230; pSC160 provides resistance to kanamycin and ampicillin. Routine plasmid maintenance and cloning utilized Escherichia coli $\mathrm{DH} 5 \alpha$. Selection and routine strain maintenance used plates made from LB or LB with various antibiotics $\left(\mathrm{LB}_{\mathrm{Km}}+\mathrm{Amp}\right.$, kanamycin, $40 \mu \mathrm{g} \mathrm{ml}^{-1}$, ampicillin, $100 \mu \mathrm{g} \mathrm{ml}^{-1} ; \mathrm{LB}_{\mathrm{Sm}}$, streptomycin, $100 \mu \mathrm{g} \mathrm{ml}^{-1}$ ), as appropriate.

\section{Construction of recombinant G. amarae strain}

Gordonia amarae chromosomal DNA was isolated using Wizard Genomic DNA purification kits (Promega). Both this DNA and pSC160 were cleaved by $S a c$ I, and random Gordonia chromosomal DNA $S a c$ I fragments were ligated into the single $S a c I$ site in the plasmid. After transformation into $E$. coli $\mathrm{DH} 5 \alpha$, recombinant strains were selected by resistance to the antibiotics ampicillin and kanamycin and sensitivity to sulphonamide and streptomycin (as the $\mathrm{Sac}$ I site lies within the $\mathrm{Sm}^{\mathrm{r}}$ gene in pKT230/pSC160). For routine screening, recombinant plasmids were isolated from DH5 $\alpha$ using the method of Holmes and Quigley [15], but isolations for use for electroporation, used QIAprep Spin Miniprep Kits
(Qiagen). Recombinant plasmids were confirmed by restriction analysis.

Gordonia amarae cells were made competent and transformed with recombinant plasmids via electroporation (Gene Pulser; Bio-Rad Laboratories) according to the manufacturer's protocol. After electroporation, presumptive recombinant strains were selected by resistance to kanamycin and ampicillin and sensitivity to streptomycin-sulphonamide. Wild type G. amarae showed natural resistance to kanamycin to some degree; therefore, kanamycin and ampicillin were used together for selection. Control electroporations using $G$. amarae cells but no DNA yielded no colonies.

\section{Confirmation of $G$. amarae transformants}

Total cell DNA was isolated from presumptive recombinant as well as untransformed G. amarae using Promega Wizard kits. PCR was run on these samples using primers which amplify a $0.3 \mathrm{~kb}$ internal portion of $v g b$ [6]. Presence of $\mathrm{VHb}$ in presumptive G. amarae transformants was determined by running $\mathrm{CO}$-difference spectra on whole cell extracts (late log-early stationary phase) according to the method of Dikshit and Webster [10]. Cell extracts were obtained (from presumptive transformants and untransformed cells) by suspending cells to $50 \mathrm{mg} \mathrm{ml}^{-1}$ in potassium phosphate, $\mathrm{pH} 7.2$ and sonicating for $10 \mathrm{~min}$, followed by centrifugation to remove cell debris. VHb levels were calculated using the extinction coefficient $E_{419-436 \mathrm{~nm}}=274 \mathrm{mM}^{-1} \mathrm{~cm}^{-1}$. BBL Columbia CNA SB agar and MacConkey agar, as well as Gram staining, were used for further characterization of the transformant.

\section{Growth measurements}

For initial growth experiments the medium was either LB [27], or mineral salts medium [5] containing $0.5 \%$ $(\mathrm{w} / \mathrm{v})$ sodium acetate trihydrate. Single colonies of the untransformed and $v g b$-bearing G. amarae were inoculated into $5 \mathrm{ml}$ of medium and grown overnight at $30^{\circ} \mathrm{C}$ and $200 \mathrm{rpm}$. For each experiment the two overnight cultures were diluted as necessary to contain an equal $\mathrm{OD}_{600}$. One hundred microliter of each diluted culture (containing 0.008 to $0.062 \mathrm{OD}_{600}$ units) was inoculated into the same medium $(100 \mathrm{ml}$ for normal aeration and $300 \mathrm{ml}$ for limited aeration) in a $500 \mathrm{ml}$ Erlenmeyer flask. In all cases this gave an $\mathrm{OD}_{600}$ at time zero of 0.000 . Incubation was at $30^{\circ} \mathrm{C}$ at either $200 \mathrm{rpm}$ (normal aeration) or $50 \mathrm{rpm}$ (limited aeration). Growth was monitored by $\mathrm{OD}_{600}$ (samples were diluted as necessary with appropriate medium to maintain measured OD's below 0.5 ) and viable counts.

Although continuous oxygen monitoring was not practical for these shake flask cultures (and those described in the following section), rough adjustment of culture oxygen levels can be obtained by variation in 
shaking speed and culture volume to vessel volume ratio $[6,16]$.

Trehalose lipid and biosurfactant measurements

For measurements of trehalose lipid and overall biosurfactant production, cells were cultured in a manner similar to that described above in LB plus $1 \%(\mathrm{v} / \mathrm{v})$ hexadecane (which is known to induce biosurfactant production [8]). Inocula were prepared from overnight LB cultures as described in the previous section. For each experiment $0.8 \mathrm{ml}$ containing an equal $\mathrm{OD}_{600}(0.31-0.35$ $\mathrm{OD}_{600}$ units) was inoculated into $800 \mathrm{ml}$ medium in 4 or 1.51 shake flasks for normal and limited aeration, respectively. In all cases this gave an $\mathrm{OD}_{600}$ at time zero of 0.000 . Homogeneity of the cultures was maintained by using vigorous agitation with a magnetic stirrer; for both normal and limited aeration the stirrer speeds were the same. Cultures were incubated at room temperature. Samples were taken periodically to measure growth (by $\mathrm{OD}_{600}$ as described above) and trehalose lipid concentration by the anthrone method [13]. Trehalose lipid determinations were made on both cells and cell free culture medium, which were separated from each other by centrifugation.

Samples from the cultures taken for trehalose lipid determinations were also used for measurements of surface tension. In these cases each sample was clarified by centrifugation and then filtered through a $0.45 \mu \mathrm{m}$ filter. Surface tension of these samples was measured by the upward pull method using a Du Nuoy ring tensiometer (Fisher Model 70535) equipped with a 6-cm circumference platinum-iridium ring. Before each experiment, the ring was rinsed with distilled water and flamed to destroy any organic matter on it. Data were collected as surface tension in dynes per centimeter. The critical micelle concentration (CMC) is the concentration of biosurfactant at which the surface tension reaches its lowest value and does not decrease any further with increased biosurfactant concentration. Each sample was serially diluted with distilled water until the surface tension increased from the lowest value. The dilution factor represents the XCMC (times CMC) of the biosurfactant concentration in the culture broth [28].
Fig. 1 CO-difference spectra of untransformed (a) and recombinant (b) G. amarae cell extracts. The (approximately) horizontal line in each panel is the baseline

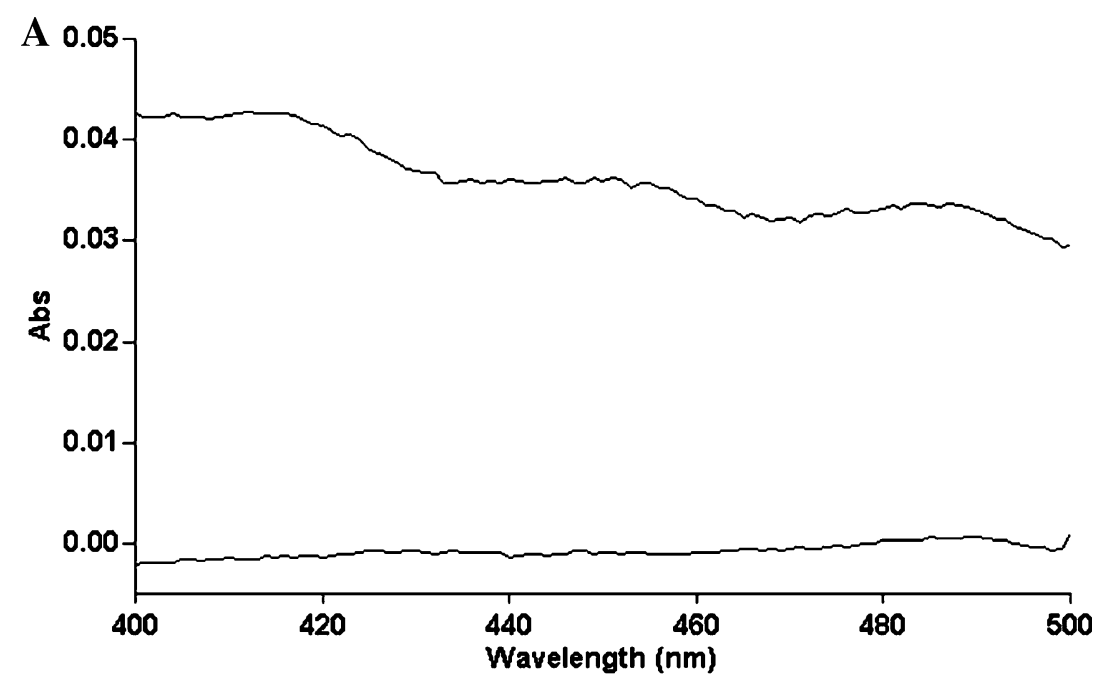

B

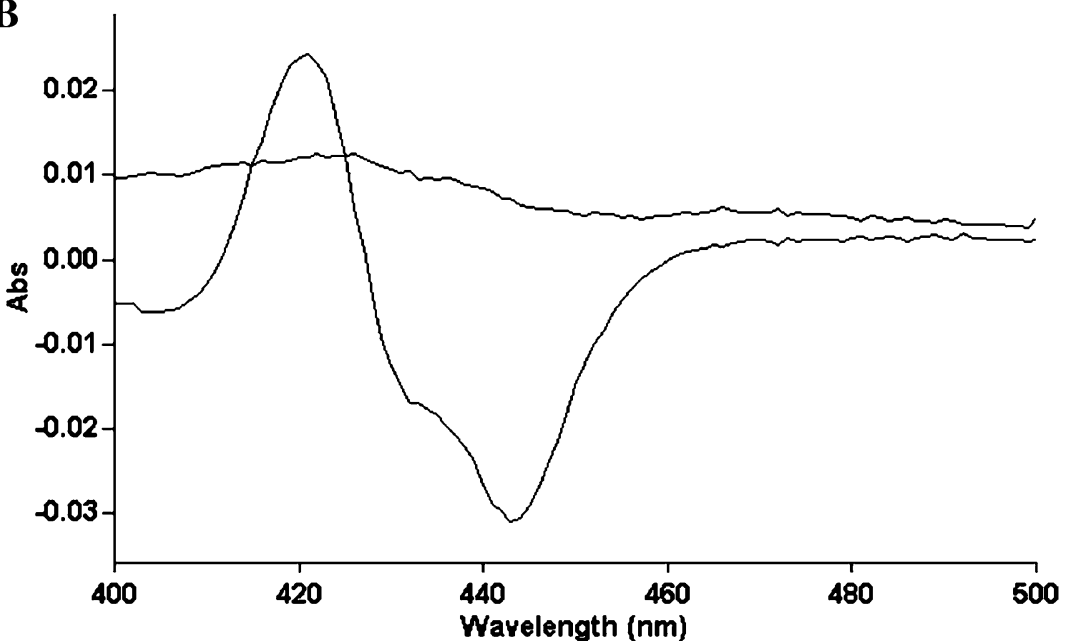




\section{Results and discussion}

Construction of recombinant plasmids and selection of $G$. amarae transformants

After the ligation of random Gordonia chromosomal DNA $S a c$ I fragments into the single $S a c$ I site in plasmid pSC160 and transformation of the ligation mixture into E. coli $\mathrm{DH} 5 \alpha$, three recombinant plasmids were identified. Large amounts of these plasmids were produced and used for electroporation into G. amarae.

Homologous recombination between the Gordonia sequence within the plasmid and the corresponding sequences in the Gordonia chromosome presumably integrated the entire plasmid, including pSC160 and thus the $v g b$ gene, into the Gordonia chromosome in each case (similar to what has been shown to occur in Thermus [18]). After 2 electroporation experiments, 11 recombinant strains were identified by resistance to kanamycin and ampicillin and sensitivity to streptomycin-sulphonamide. It is also possible that pSC160 can exist autonomously in $G$. amarae, although the likelihood for that event is unknown. Plasmid pSC160, however, is derived from plasmid RSF1010, which belongs to the Inc $\mathrm{Q} / \mathrm{P} 4$ plasmid incompatibility group that can be propagated in a very extensive host range extending to Gram-positive bacteria and eukaryotes [26, $34,37]$. One of the recombinant strains (from electroporation using a recombinant plasmid with a $5.5 \mathrm{~kb}$ insert) was chosen for further studies.

\section{Confirmation of $v g b$-bearing G. amarae}

The presence of $v g b$ in the recombinant G. amarae strain was verified by PCR using a set of primers that amplify a $0.3 \mathrm{~kb}$ portion of $v g b$. Untransformed G. amarae was used as a negative control. Only genomic DNA from the recombinant $G$. amarae produced a $0.3 \mathrm{~kb}$ fragment identical in size to that amplified using plasmid pSC160 as template.

$\mathrm{VHb}$ expression was checked using CO-difference spectra (in which $\mathrm{VHb}$ has a characteristic absorption maximum at $419 \mathrm{~nm}$ and minimum at $436 \mathrm{~nm}$ [10]). Cell free extracts from untransformed $G$. amarae showed neither peak nor trough, while the recombinant G. amarae cell free extracts showed a peak at approximately $420 \mathrm{~nm}$, that was broader than that observed in Vitreoscilla or E. coli expressing $\mathrm{VHb}$ [10], and a trough at about $445 \mathrm{~nm}$ with a shoulder near $435 \mathrm{~nm}$ (Fig. 1). The reasons for these changes from the standard spectrum are unknown, but similar changes to the $\mathrm{VHb} \mathrm{CO}-$ spectrum have also been observed in Pseudomonas aeruginosa [22] and Burkholderia cepacia [6].

The VHb level for the recombinant strain was about 4 nmole $\mathrm{g}^{-1}$ wet weight of cells, which is about eightfold lower than that seen in Vitreoscilla and about 60-fold lower than $E$. coli bearing $v g b$ on a high copy number plasmid [10]. This is somewhat lower than levels which resulted in positive effects in Pseudomonas $\left(8.8 \mathrm{nmol} \mathrm{g}^{-1}\right)$ but higher than those that were not effective in Burkholderia $\left(0.8 \mathrm{nmol} \mathrm{g}^{-1}\right)$ [6]. It is, however, the lowest level we have found so far that is beneficial to any of the species we have transformed with the $\mathrm{VHb}$ gene.

\section{Characteristics of the recombinant strain}

Both transformed and untransformed $G$. amarae grew on BBL Columbia CNA SB agar (supports growth for only Gram-positive bacteria) but not MacConkey agar (supports growth for only Gram-negative bacteria). Colonies of the transformant on LB plates were about twice the diameter of those of the untransformed strain. Gram staining showed that both the untransformed G. amarae (approximately 90\% Gram-positive and 10\% Gram-negative) and the recombinant G. amarae (approximately 10\% Gram-positive and 90\% Gramnegative) were Gram-variable. Gordonia are known to be Gram-variable [1], but the reason(s) for the difference

Table 1 Growth of the untransformed ("wt") and hemoglobinbearing ("rec") strains as measured by both OD $_{600}$ and viable cell counts as described in the text

\begin{tabular}{lll}
\hline Strain, medium, aeration & $\mathrm{OD}_{600}$ & Time $(\mathrm{h})$ \\
\hline OD 600 & & \\
wt, min, normal aeration & $0.055(0.001)$ & 120 \\
rec, min, normal aeration & $0.19(0)$ & 72 \\
wt, min, limited aeration & $0.037(0.003)$ & 120 \\
rec, min, limited aeration & $0.12(0.002)$ & 120 \\
wt, LB, normal aeration & $1.13(0.03)$ & 72 \\
rec, LB, normal aeration & $3.15(0.12)$ & 96 \\
wt, LB, limited aeration & $0.16(0.004)$ & 120 \\
rec, LB, limited aeration & $0.54(0.06)$ & 96 \\
wt, LB + hexadecane, & $1.08(0.12)$ & 96 \\
normal aeration & & \\
rec, LB + hexadecane, & $2.50(0.04)$ & 120 \\
normal aeration & & \\
wt, LB + hexadecane, & $0.80(0.14)$ & 144 \\
limited aeration & & \\
rec, LB + hexadecane, & $1.45(0.45)$ & 72 \\
limited aeration & & 72 \\
Viable cell counts & & 72 \\
wt, min, normal aeration & $2.63 \mathrm{E}+08(2.30 \mathrm{E}+07)$ \\
rec, min, normal aeration & $2.54 \mathrm{E}+09(7.21 \mathrm{E}+07)$ & 96 \\
wt, min, limited aeration & $8.00 \mathrm{E}+07(2.07 \mathrm{E}+06)$ & 48 \\
rec, min, limited aeration & $1.10 \mathrm{E}+09(8.02 \mathrm{E}+07)$ & 96 \\
wt, LB, normal aeration & $5.00 \mathrm{E}+09(1.97 \mathrm{E}+07)$ & 48 \\
rec, LB, normal aeration & $3.00 \mathrm{E}+10(1.91 \mathrm{E}+09)$ & 48 \\
wt, LB, limited aeration & $5.11 \mathrm{E}+08(8.00 \mathrm{E}+05)$ & 24 \\
rec, LB, limited aeration & $1.70 \mathrm{E}+09(7.21 \mathrm{E}+07)$ & 96 \\
\hline
\end{tabular}

Data are maximum values for growth under both normal and limited aeration, and in LB, LB plus $1 \% \mathrm{v} / \mathrm{v}$ hexadecane, and mineral salts ("min") media. Values are averages of three replicates (standard deviations in parentheses). Data were collected for $144 \mathrm{~h}$ for the experiments using LB plus hexadecane and $120 \mathrm{~h}$ for all other experiments; data points were taken at $0 \mathrm{~h}$ (inoculation) and at 4-24 h intervals thereafter; values in the rightmost column are times at which each maximum occurred. Experiments utilizing LB plus hexadecane measured only $\mathrm{OD}_{600}$ (and not viable counts) 
we see between transformed and untransformed strains in this property is not known. Gram variability has been shown to be related to the growth stage for a number of bacteria [3], which indicates that changes in the physiological state of cells could be its cause. The presence of Vitreoscilla hemoglobin (VHb) in E. coli cells has been shown to result in significant changes in the expression of hundreds of genes compared to cells which were not transformed with $\mathrm{VHb}$ [33]. If similar changes in gene expression occur in Gordonia, they might also lead to significant physiological changes which, in turn, affect Gram staining.

Despite its difference from the untransformed strain in Gram staining and colony characteristics, the identity of the transformed strain as G. amarae is supported by the following: (a) control electroporations using our $G$. amarae cultures and no DNA never gave any colonies, lessening the probablility that some contaminant was present in the electroporated samples; (b) the transformants had precisely the drug resistance/sensitivity expected, which would be unlikely to occur from a random contaminant; (c) both transformant and untransformed cells grew on CNA SB agar, but neither grew on MacConkey agar; and (d) both transformant and untransformed cells produced extracellular biosurfactant and trehalose lipid.
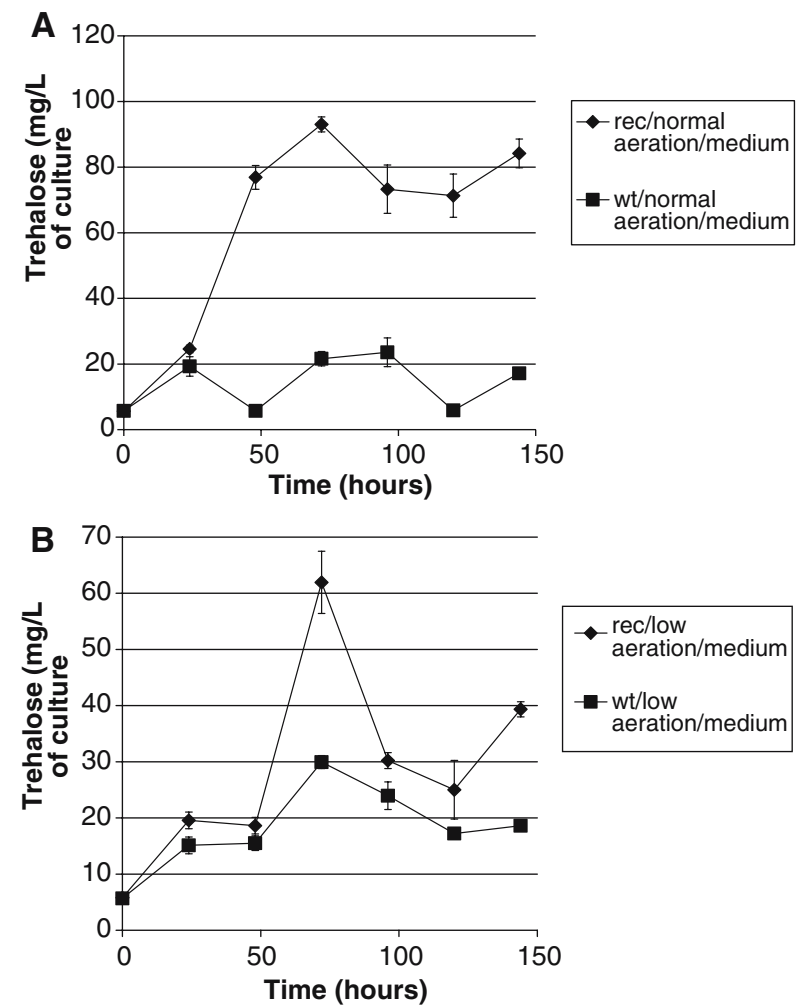

Fig. 2 Intra- and extracellular (medium) trehalose lipid concentrations (expressed as milligram trehalose per liter of culture) for the recombinant ( $\mathrm{rec}$ ) and the non-transformed (wt) strains grown under both normal and low aeration. a Medium concentrations for normal aeration; b medium concentrations for low aeration; c intracellular concentrations for normal aeration; d intracellular
The transformed strain was stable as indicated by its retention of both the antibiotic resistance provided by the vector $\mathrm{pSC} 160$ (which will remain with $v g b$ whether on the plasmid or integrated into the host chromosome) and colony morphology upon repeated transfer of the recombinant strain over many months.

\section{Growth comparisons}

Growth of untransformed and $v g b$-bearing $G$. amarae was compared in three different media for both normal and limited aeration (Table 1). In both LB and mineral salts medium plus sodium acetate and at both aerations the presence of $v g b / \mathrm{VHb}$ provided a substantial advantage regarding both maximum $\mathrm{OD}_{600}$ and maximum viable cells. The advantages regarding $\mathrm{OD}_{600}$ ranged from $2.8 \mathrm{X}$ to $3.5 \mathrm{X}$ and were similar at both aerations. The advantages regarding viable cells ranged from $3.3 \mathrm{X}$ to $14 \mathrm{X}$ and were greater in mineral salts medium. When cells were grown in LB plus hexadecane the advantages in maximum $\mathrm{OD}_{600}$ were $1.8 \mathrm{X}$ and $2.3 \mathrm{X}$ for the $\mathrm{VHb}$ producing cells at limited and normal aerations, respectively. These figures are within the ranges seen in previous work. In some cases the presence of $\mathrm{VHb}$ in recombinant bacteria has resulted in no growth
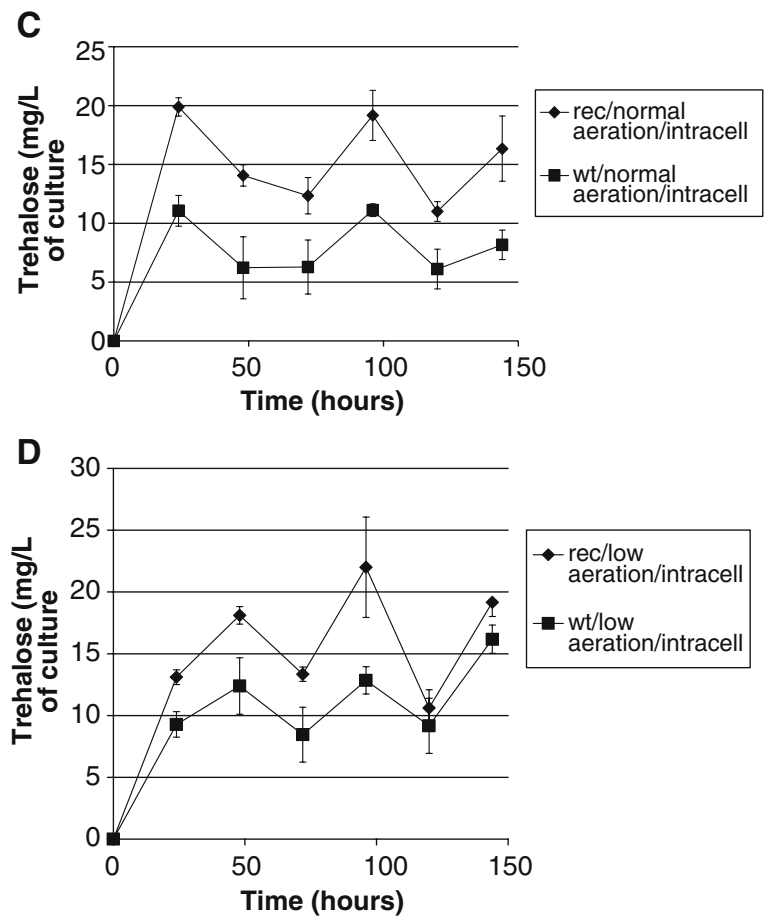

concentrations for low aeration. Times indicate hours after inoculation that samples were taken. Growth data for the cultures are the last four entries in Table $1, \mathrm{OD}_{600}$; late log phase was about $72 \mathrm{~h}$ for the recombinant strain under low aeration and about $48 \mathrm{~h}$ otherwise. Values are averages of three individual measurements. Error bars indicate standard deviations 
advantage or even a slight growth disadvantage compared to $\mathrm{VHb}-$ free cells $[4,22]$, and sometimes to advantages as high as $2-3 \mathrm{X}$ on a dry cell mass basis [38] and as high as about 40X on a viable cell basis [39].

Trehalose lipid and overall biosurfactant determinations

Growth in LB plus hexadecane was also used to measure trehalose lipid production. This compound is a component of $G$. amarae produced biosurfactant, although its percentage of total biosurfactant is unknown. Biosurfactants include a variety of compounds, among which glycolipids are the major fraction [12]. As trehalose lipid is one of these glycolipids, its measurement is a useful indicator of biosurfactant production. Our measurement of overall biosurfactant levels (discussed below) supplemented the trehalose data to provide a more complete picture of biosurfactant levels. Hexadecane was included in the medium, as biosurfactant production is significantly greater when a hydrophobic carbon source is added to the growth medium [28]. The details of the genetics of this hexadecane effect, however, are not known.

The presence of $\mathrm{VHb}$ enhanced trehalose lipid production in the recombinant strain in both the broth and in cells (Fig. 2). Under normal aeration, the recombinant strain improved the maximum trehalose lipid level in the medium and cells by $4.0 \mathrm{X}$ and $1.8 \mathrm{X}$, respectively. Under limited aeration, the same advantages of the recombinant strain were $2.1 \mathrm{X}$ and $1.4 \mathrm{X}$, respectively. These differences in maximum biosurfactant levels are significant because biosurfactant would be harvested in batch experiments at these peaks. The levels of both intra- and extracellular (i.e., medium) trehalose lipid were determined for sake of completeness. The extracellular levels are perhaps most important, however, because of the relative ease of harvesting trehalose lipid from the medium.

The levels of trehalose lipid measured for G. amarae by Pagilla et al. [28] were similar to those found in this study both in order of magnitude and in the cyclical nature of maxima and minima as a function of time in culture. This cyclical pattern is thought to be due to repeated periods of biosurfactant production, consequent solubilization of hexadecane, uptake of hexadecane and biosurfactant, and biodegradation of biosurfactant.

Another measure of biosurfactant production during growth is surface tension of the culture medium, which decreases with increased biosurfactant production, and after reaching a threshold, does not change further. As mentioned above, this threshold biosurfactant concentration is called the CMC. This technique is commonly used to measure the extent of biosurfactant production and is represented as XCMC [28]. For growth at both normal and limited aeration there was a greater production of biosurfactant (by this measurement) for the $v g b$-bearing strain as compared to its untransformed counterpart, and these differences paralleled roughly the differences seen in trehalose lipid production between the two strains (Fig. 3). As was the case for trehalose lipid, the difference between $v g b$-bearing and untransformed strains was greater at normal than at limited aeration.

That the time courses of trehalose lipid measurements and biosurfactant levels determined by the surface tension assay are not identical is perhaps not surprising, since the surface tension data are a measure of total biosurfactant, of which trehalose lipid is only one component.

The presence of $\mathrm{VHb}$ is usually, although not always, most effective regarding its positive effects when cells are grown in limited aeration conditions [35]. In the case of G. amarae, the positive effects (growth, trehalose lipid production, overall biosurfactant production) are similar or greater at normal versus limited aeration. The reasons for this are not known, but in Vitreoscilla, E. coli, and perhaps other bacteria, VHb levels increase under hypoxic conditions (thus, presumably leading to a greater relative advantage of VHb-producing cells when aeration is limited), and this may not occur in
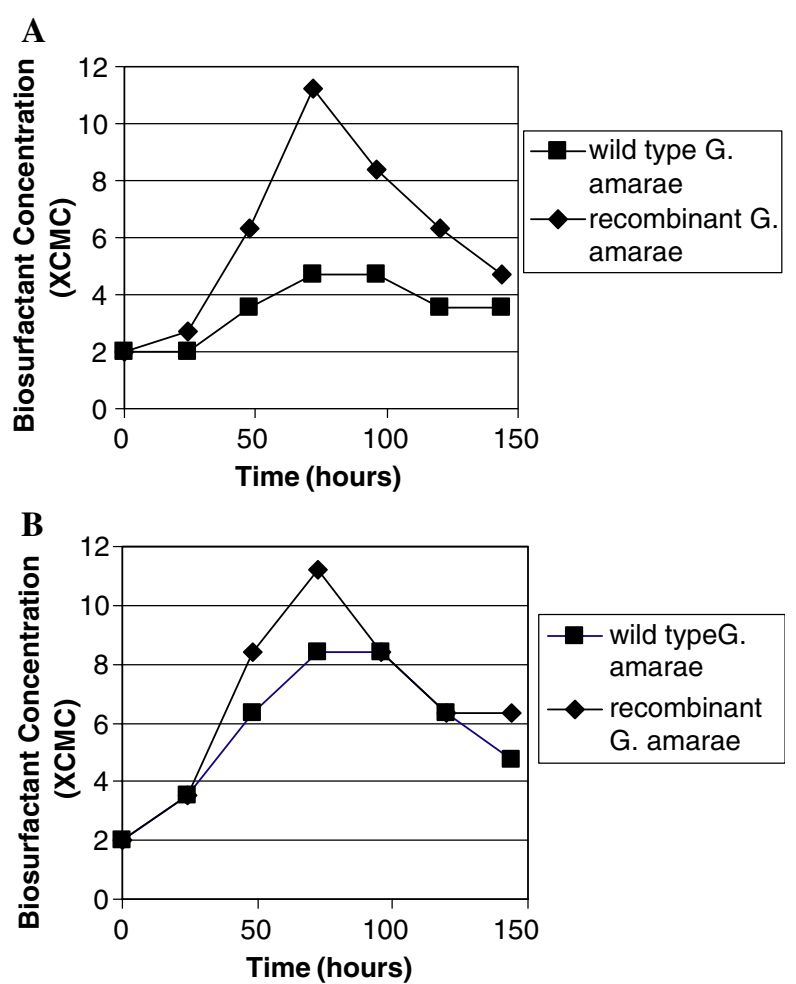

Fig. 3 Biosurfactant concentration [at normal (a) and limited (b) aeration] in cell free culture medium (measured in terms of XCMC) versus growth time. For each time point, data from identical dilution series of medium from three replicate cultures were averaged and used to construct a surface tension versus log dilution plot. From each plot, one of the data points in $\mathbf{a}$ and $\mathbf{b}$ was calculated, using the method referenced in the text. Times indicate hours after inoculation that samples were taken. Growth data for the cultures are the last four entries in Table $1, \mathrm{OD}_{600}$; late log phase was about $72 \mathrm{~h}$ for the recombinant strain under low aeration and about $48 \mathrm{~h}$ otherwise 
G. amarae. It is also possible that the uptake of dissolved oxygen (DO) may be very high when hexadecane is present in the growth medium as an additional carbon source, and limited aeration conditions may not be sufficient to provide sufficient DO, even with $\mathrm{VHb}$. In fact, Pagilla et al. [28] used pure oxygen instead of air to supply DO when $1 \%$ hexadecane was used for biosurfactant production with this species.

In summary, then, genetic engineering of biosurfactant producing strains with $v g b$ may be an effective method to increase biosurfactant production. This approach may be useful in both in situ applications, where inoculation of an engineered bacterial strain into a site contaminated with a sparingly soluble chemical can continuously produce biosurfactant to enhance metabolism of this compound by itself or another species, or for enhanced production of biosurfactant for purification and utilization in that form to replace synthetic surfactants.

Acknowledgements This work was supported by NSF grant number MCB-9910356. We thank Dr. John Kilbane for helpful discussions, Dr. Kevin Kayser for help with electroporation, and Dr. Sangeeta Patel for help with the Gram staining.

\section{References}

1. Arenskotter M, Broker D, Steinbuchel A (2004) Biology of the metabolically diverse genus Gordonia. Appl Environ Microbiol 70:3195-3204

2. Banat IM, Makkar RS, Cameotra SS (2000) Potential commercial applications of microbial surfactants. Appl Microbiol Biotechnol 53:495-508

3. Beveridge TJ (1990) Mechanism of gram variability in select bacteria. J Bacteriol 172:1609-1620

4. Buddenhagen RE, Webster DA, Stark BC (1996) Enhancement by bacterial hemoglobin of amylase production in recombinant E. coli occurs under conditions of low $\mathrm{O}_{2}$. Biotechnol Lett 18:695-700

5. Cha DK (1990) Process control factors influencing Nocardia populations in activated sludge. PhD Dissertation, University of California, Berkley

6. Chung JW, Webster DA, Pagilla KR, Stark BC (2001) Chromosomal integration of the Vitreoscilla hemoglobin gene in Burkholderia and Pseudomonas for the purpose of producing stable engineered strains with enhanced bioremediating ability. J Ind Microbiol Biotechnol 27:27-33

7. Cooper DG, Zajic JE (1980) Surface active compounds from microorganisms. Adv Appl Microbiol 26:229-253

8. Davis JB (1964) Cellular lipids of a Nocardia grown on propane and n-butane. Appl Microbiol 12:301-304

9. De Modena JA, Gutierrez S, Velasco J, Fernandez FJ, Fachini RA, Galazzo JL, Hughes DE, Martin JF (1993) The production of cephalosporin $\mathrm{C}$ by Acremonium chrysogenum is improved by the intracellular expression of a bacterial hemoglobin. Biotechnology 11:926-929

10. Dikshit KL, Webster DA (1988) Cloning, characterization and expression of the bacterial globin gene from Vitreoscilla in $E$. coli. Gene 70:377-386

11. Farres J, Kallio PT (2002) Improved cell growth in tobacco suspension cultures expressing Vitreoscilla hemoglobin. Biotechnol Prog 18:229-233

12. Georgiou G, Lin S-C, Sharma MM (1992) Review of surfaceactive compounds from microorganisms. Biotechnology 10:6065
13. Hodge JE, Hofreiter BT (1962) Determination of reducing sugars and carbohydrates. Methods Carbohydr Chem 1:389390

14. Holmberg N, Lilius G, Bailey JE, Bulow L (1997) Transgenic tobacco expressing Vitreoscilla hemoglobin exhibits enhanced growth and altered metabolite production. Nat Biotechnol 15:244-247

15. Holmes DS, Quigley M (1981) A rapid boiling method for the preparation of bacterial plasmids. Anal Biochem 114:193-197

16. Kallio PT, Kim DJ, Tsai PS, Bailey JE (1994) Intracellular expression of Vitreoscilla hemoglobin alters Escherichia coli energy metabolism under oxygen-limited conditions. Eur J Biochem 219:201-208

17. Kang DG, Kim JYH, Cha HJ (2002) Enhanced detoxification of organophosphates using recombinant Escherichia coli with coexpression of organophosphorus hydrolase and bacterial hemoglobin. Biotechnol Lett 24:879-883

18. Kayser KJ, Kilbane JJ (2001) New host-vector system for Thermus spp. based on the malate dehydrogenase gene. J Bacteriol 183:1792-1795

19. Lang S, Wagner F (1987) Structure and properties of biosurfactants. In: Kosaric N, Cairns WL (eds) Biosurfactants and biotechnology. Marcel Dekker, New York, pp 21-46

20. Lee SY, Stark BC, Webster DA (2004) Structure-function studies of the Vitreoscilla hemoglobin D-region. Biochem Biophys Res Commun 316:1101-1106

21. Lin JM, Stark BC, Webster DA (2003) Effects of Vitreoscilla hemoglobin on the 2,4-dinitrotoluene (DNT) dioxygenase activity of Burkholderia and on DNT degradation in two-phase bioreactors. J Ind Microbiol Biotechnol 30:362-368

22. Liu SC, Webster DA, Stark BC (1995) Cloning and expression of the Vitreoscilla hemoglobin gene in Pseudomonads: effects on cell growth. Appl Microbiol Biotechnol 44:419-424

23. MacDonald CR, Cooper DG, Zajic JE (1981) Surface-active lipids from Nocardia erythropolis grown on hydrocarbons. Appl Environ Microbiol 41:117-123

24. Magnolo SK, Leenutaphong DL, De Modena JA, Curtis JE, Bailey JE, Galazzo JL, Hughes DE (1991) Actinorhodin production by Streptomyces coelicolor and growth of Streptomyces lividans are improved by the expression of a bacterial hemoglobin. Biotechnology 9:473-476

25. Margaritis A, Kennedy K, Zajic JE, Gerson DF (1979) Biosurfactant production by Nocardia erythropolis. Dev Ind Microbiol 20:623-630

26. Mazodier P, Petter R, Thompson C (1989) Intergeneric conjugation between E. coli and Streptomyces species. J Bacteriol 171:3583-3585

27. Miller JH (1972) Experiments in molecular genetics. Cold Spring Harbor Laboratory, Cold Spring Harbor

28. Pagilla KR, Kim H, Sood A (2002) Gordonia amarae foaming due to biosurfactant production. Water Sci Technol 46:519-524

29. Parales RE, Bruce NC, Schmid A, Wackett LP (2002) Biodegradation, biotransformation, and biocatalysis (B3). Appl Environ Microbiol 68:4699-4709

30. Park KW, Kim KJ, Howard AJ, Stark BC, Webster DA (2002) Vitreoscilla hemoglobin binds to subunit I of cytochrome bo ubiquinol oxidases. J Biol Chem 277:33334-33337

31. Pendse GJ, Bailey JE (1994) Effect of Vitreoscilla hemoglobin expression on growth and specific tissue plasminogen activator productivity in recombinant Chinese hamster ovary cells. Biotechnol Bioeng 44:1367-1370

32. Ramendeep, Hwang KW, Raje M, Kim KJ, Stark BC, Dikshit KL, Webster DA (2001) Vitreoscilla hemoglobin: intracellular localization and binding to membranes. $\mathbf{J}$ Biol Chem 276:24781-24789

33. Roos V, Andersson CIJ, Bulow L (2004) Gene expression profiling of Escherichia coli expressing double Vitreoscilla haemoglobin. J Biotechnol 114:107-120

34. Schafer A, Kalinowski J, Simon R, Seep-Feldhaus A-H, Puhler A (1990) High-frequency conjugal plasmid transfer from Gram-negative $E$. coli to various Gram-positive coryneform bacteria. J Bacteriol 172:1663-1666 
35. Stark BC, Webster DA, Dikshit KL (1999) Vitreoscilla hemoglobin: molecular biology, biochemistry, and practical applications. Recent Res Dev Biotech Bioeng 2:155-174

36. Sutton R (1992) Removal of sparingly soluble organic chemicals from aqueous solutions by biosurfactants produced by Nocardia amarae. MS Thesis, Illinois Institute of Technology, Chicago

37. Trieu-Cuot P, Carlier C, Martin P, Courvalin P (1987) Plasmid transfer by conjugation from $E$. coli to Gram-positive bacteria. FEMS Microbiol Lett 48:289-294

38. Tsai PS, Hatzimanikatis V, Bailey JE (1996) Effect of Vitreoscilla hemoglobin dosage on microaerobic Escherichia coli carbon and energy metabolism. Biotechnol Bioeng 49:139-150
39. Urgun-Demirtas M, Pagilla KR, Stark BC, Webster DA (2003) Biodegradation of 2-chlorobenzoate by recombinant Burkholderia cepacia expressing Vitreoscilla hemoglobin under variable levels of oxygen availability. Biodegradation 14:357-365

40. Urgun-Demirtas M, Pagilla KR, Stark BC (2004) Enhanced kinetics of genetically engineered Burkholderia cepacia: role of $v g b$ in the hypoxic metabolism of 2-CBA. Biotechnol Bioeng 87:110-118 